\title{
Feeding before exercise and competition in the performance horse
}

\author{
Patricia A Harris \\ Equine Studies Group, WALTHAM Centre For Pet Nutrition, Melton Mowbray, Leics, UK
}

\begin{abstract}
Summary
There has been considerable debate across the years about when and what should be fed to performance horses (eventers, show- jumpers, endurance horses etc.) before they are exercised and/or at a competition in order to reduce the risk of gastrointestinal disturbances and other adverse sequellae. Should they be fed or fasted and when should the hay be fed in relation to the grain and/or exercise? This paper reviews, in particular, some of the work that WALTHAM and its collaborators around the world have done in this area.
\end{abstract}

Keywords: Nutrition, competition, endurance, eating rate, glycaemic response.

\section{Fütterung von Sportpferden vor dem Training und vor Wettkämpfen}

\begin{abstract}
Über das „Wann“ und "Was" Sportpferden (Vielseitigkeits-, Spring-, Distanzreitpferde, etc.) vor dem Training bzw. bei Wettkämpfen gefüttert werden sollte, um gastrointestinalen Störungen und anderen negativen ernährungsbedingten Folgeerscheinungen vorzubeugen, wird seit Jahren heftig diskutiert. Sollten sie früher gefüttert werden oder fasten, und wann sollte die Heuaufnahme in Verbindung mit der Kraftfutteraufnahme und/oder dem Training erfolgen? Der folgende Artikel gibt eine Übersicht insbesondere über die Arbeit der Fa. WALTHAM und ihrer Mitarbeiter weltweit zu diesem Thema.
\end{abstract}

Schlüsselwörter: Ernährung, Wettkampf, Ausdaver, Futteraufnahmerate, Blutzuckerverlauf

\section{Substrate utilisation}

\section{Fed Vs Fasted: Grain Vs Forage}

One of the first studies published on this aspect (Pagan et al 1995) looked at the influence of time of feeding on exercise response in thoroughbreds fed a fat supplemented or a more traditional high carbohydrate diet. Horses were exercised either after an overnight fast or 3 or 8 hours after their concentrate meal. This initial study showed that the time of feeding affected the plasma glucose and insulin concentrations not only before and during the exercise but also afterwards. Horses fed the cereal based ration 3 hours before exercise experienced large decreases in blood glucose levels during exercise due to the elevated insulin levels at the beginning of the standardised exercise test. Time of feeding rather than the type of diet therefore affected the blood glucose levels during exercise. However, post exercise the glucose levels were higher at 15 and 30 mins when fed the oil supplemented diet. Three subsequent studies were conducted (Pagan and Harris 1999) in order to look at whether feeding hay with or without grain affected the glycaemic and haematological response in thoroughbred horses at rest and during a simulated competition exercise test (CET: the cross country day at a $3 D E$ ). The first study with resting horses (hay given 4 hrs after the grain or grain given either with, or, 2 hrs after the hay) showed that when hay was fed before or with grain it affected the glycaemic response to the grain meal. Whilst the glycaemic response decreased, the total protein concentrations and water intake both increased. It was thought that this might be as a result of an increased rate of passage of grain through the gastrointestinal tract when the hay was present. This could in turn result in reduced digestion of the grain in the small intestine especially if a large grain meal is fed.
The second study looked at whether exercising horses should receive hay before, with, or after a grain meal (the treatments were Fast: overnight fast; Grain plus ad lib Hay: ad lib hay the night before and before the CET plus $\sim 2.3 \mathrm{~kg}$ of a grain based meal $2 \mathrm{hrs}$ prior to the CET; Grain plus Hay: $\sim 2.3 \mathrm{~kg}$ hay $3 \mathrm{hrs}$ before the CET and $\sim 2.3 \mathrm{~kg}$ feed $2 \mathrm{hrs}$ prior to the CET; Grain: $\sim 2.3 \mathrm{~kg}$ of feed $2 \mathrm{hr}$ prior to the exercise with $\sim 2.3 \mathrm{Kg}$ hay at $10 \mathrm{pm}$ the night before). Plasma volume was determined immediately before exercise using an indocyanine green clearance method. Feeding hay either alongside the grain or ad libitum resulted in reduced plasma volume and higher lactate production as well as higher heart rates during the exercise. Fasted horses had lower blood lactate after the 8-min canter compared to the others. Feeding grain reduced the free fatty acid availability and, as before, increased the blood glucose disappearance during exercise due to higher insulin concentrations (see Figs 1 and 2). However, it should be pointed out that the ad-lib hay group had higher bodyweights (as they were not accustomed to such a diet) than the other groups.

The third study was carried out to look at whether feeding forage but no grain would affect substrate utilisation and performance through looking at fasting, versus $2.3 \mathrm{~kg}$ hay $3 \mathrm{hrs}$ before the CET; versus ad lib hay the night before the CET, versus overnight grazing in a grass paddock prior to the CET. This showed that feeding forage before exercise did not appear to adversely affect performance (other than the potential to increase body weight and possibly reduce plasma volume if intake was not controlled). Feeding forage only before exercise had a much smaller effect on the glycaemic and insulin responses than a grain meal and there was no effect on free fatty acid availability. The horses that had been grazing befo- 
re the CET tended to be heavier but did not show the same changes in plasma volume or heart rate as they did with the forage, perhaps because of fluid equilibration.

The conclusions from these studies were that grain should be withheld from horses before sport-like exercise i.e. do not feed a cereal based concentrate meal within 2 - 3hrs of exercise to horses undertaking sport horse like exercise. However, small amounts of hay should be fed to help ensure healthy gastrointestinal function and to minimise the risk of gastric ulceration but weight gain should be limited.

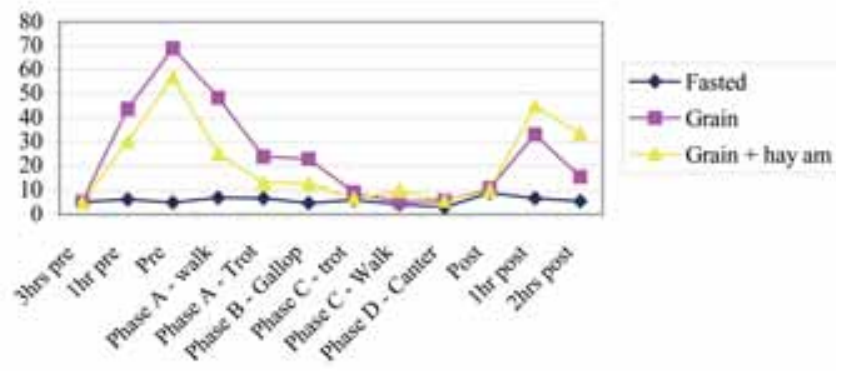

Fig 1 Plasma Insulin concentrations $(\mathrm{U} / \mathrm{ml})$ before during and after a simulated competition exercise test (CET: Pagan and Harris 1999). Plasmainsulin-Konzentrationen $(\mathrm{u} / \mathrm{ml}$ ) vor, während und nach einem simulierten Rennbelastungstest.

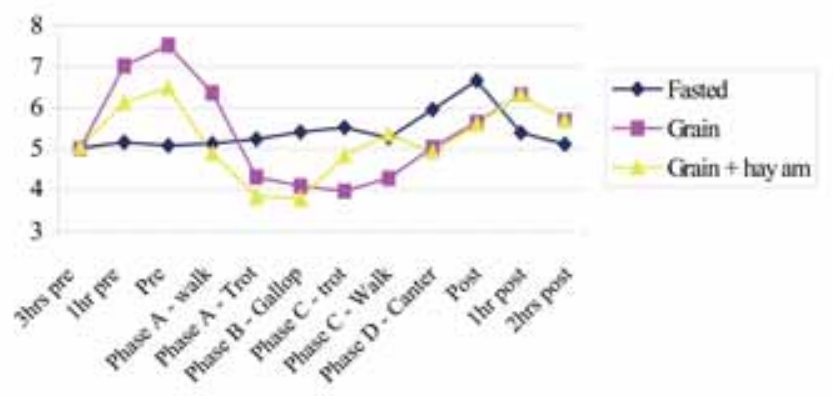

Fig 2 Plasma Glucose concentrations ( $\mathrm{mmol} / \mathrm{L}$ ) before, during and after a simulated competition exercise test (CET: Pagan and Harris 1999)

Plasmaglucose-Konzentrationen ( $\mathrm{mmol} / \mathrm{l})$ vor, während und nach einbem simulierten Rennbelastungstest.

There is, therefore, evidence from the above and other studies that the timing and composition of a meal consumed before exercise can influence the metabolic response in horses (Lawrence et al. 1993, Lawrence et al.1995, Stull and Rodiek 1995, Pagan et al 1995, Pagan and Harris 1999, Harris and Graham-Theirs 1999). In particular, the hyperglycaemia and insulinemia associated with the digestion and absorption of grain meals affects the mix of substrates utilised during a bout of exercise. Insulin is a potent inhibitor of lipolysis and fatty acid oxidation in skeletal muscle, and also promotes glucose uptake into muscle via recruitment of the transporter protein GLUT4 to the sarcolemma. Thus, hyperinsulinemia at exercise onset will suppress NEFA availability and lipid oxidation and increase reliance on carbohydrate stores (including plasma glucose) for energy transduction. The decrease in plasma glucose noted above tends to be relatively short term, however, plasma NEFA and lipid oxidation may remain lower in fed animals when compared to the fasted state throughout certain types of exercise (Jose-Cunilleras et al. 2002).

There has been little work concentrating on the effects of feed type and timings pre more short-term intensive exercise. In one study, where $\sim 1 \mathrm{~kg}$ of hay and $\sim 1 \mathrm{~kg}$ of cereals were fed, around $1.5-2 \mathrm{hrs}$ pre a simulated trotting race $(2600 \mathrm{~m}$ on a $2.5 \%$ incline at around $90 \%$ of $\mathrm{VO}_{2}$ max), no differences in glucose and insulin values were found between the pre-exercise samples and resting pre- prandial samples (PalmgrenKarlsson et al. 2002).

\section{Restricted Vs Ad lib forage}

Bodyweight and gut fill are important considerations for the racehorse - for every kilogram of dry hay around $2.5-3.5 \mathrm{~kg}$ of water may be consumed which will add to the weight of the horse and potentially adversely affect performance. However, it is well appreciated that prolonged fasting can result in an unwanted reduction in liver glycogen levels as well as the level of hydration but perhaps more importantly in the short term fasting may increase the risk of gastric ulceration especially when followed by intensive exercise. In subsequent studies we looked at the effect of restricted hay intake (for 3 days at $1 \%$ BW) compared to ad libitum feeding. This resulted in a decrease of approximately $2 \%$ in BW, which was associated with an increase in the mass specific rate of oxygen consumption during sprint exercise with a corresponding decrease in anaerobic energy expenditure (Rice et al 2001). However, as very few horses in intense performance work are currently fed ad lib forage, further work is needed to determine the exact nature and level of optimal amounts to be fed for such animals.

\section{Conclusion}

In conclusion, studies in horses have demonstrated that forage meals $(<2 \mathrm{~kg}$, as fed) consumed 2 to 3 hours before exercise have minimal effect on substrate availability and oxidation during sustained exertion, although large meals (hay or grain or a combination) consumed near the start of exercise may result in a decrease in plasma volume as a result of fluid shifts into the gastrointestinal tract (Pagan and Harris 1999). Such reductions in plasma volume could compromise cardiovascular and thermoregulatory function during exercise. Restricting forage intake for prolonged periods of time, however, increases the risk of gastric ulceration. Current recommendations are therefore to allow the consumption of small forage meals (1-2 kg, as fed) in the 1-3 h period precompetition (Geor and Harris 2005).

\section{Effect of time taken to eat}

It is not always possible to work horses, especially during training, 3hrs after a small meal. However, especially in quick or greedy eaters eating a concentrate-based meal can result in a significant decrease in plasma volume. Adult horses, around $500 \mathrm{~kg} \mathrm{BW}$, may secrete more than $100 \mathrm{~L}$ of fluid per day into the pre-caecal section of the gastrointestinal tract i.e. around $70-100 \mathrm{ml} /$ minute (Harris et al 2006). When large meals of either pellets or cereal grains are fed infrequently a 
transient state of hypovolaemia occurs as a result of meal stimulated upper gastrointestinal secretions. Within one hour of feeding ponies there has been shown to be on average a $15 \%$ loss in plasma volume. In quick or greedy feeders this can be up to a $24 \%$ loss (Clarke et al 1990). Slow feeders compensate whilst they eat and the resultant volume losses are therefore small. These changes in plasma volume are not seen when frequent small meals are fed.

Slowing down quick and greedy feeders can obviously be advantageous. The provision of sufficient supplemental chaff at an appropriate chop length therefore may be beneficial. In one study, for example, (Ellis et al 2005) the effects of including $10 \%, 20 \%$ or $30 \%$ of straw chopped into either $2.5 \mathrm{~cm}$ or $4 \mathrm{~cm}$ lengths to a trial pellet fibre mix (containing 10\% short cropped lucerne) were evaluated. Between 1 and $1.2 \mathrm{~kg}$ of the mix was fed to horses each morning and evening, and a number of parameters recorded. The rate of chewing remained about the same regardless of the type of food fed, but the type of food had a significant effect on the rate of intake and the total number of chews per $\mathrm{kg}$. Diets containing added straw were eaten significantly more slowly than their normal diet mix, their normal pellets and the trial pellets on their own (see Fig 3). There was, however, no significant effect of adding 10\% straw chaff to the trial pellets with 10\% chopped alfalfa but there was a significant effect of the $20 \%$ and $30 \%$ addition. Whilst adding more than $20 \%$ of the straw chaff had no significant effect the intake rate did decrease and the time taken to eat the meal increased. Average food intake times ranged from $7 \mathrm{~min} / \mathrm{kg}$ on the normal diet to $16 \mathrm{~min} / \mathrm{kg}$ when the longer chaff was included at $30 \%$ to the pellet/chaff mix. There was no significant difference between the long and short fibre lengths at any of the three inclusion rates. These results indicate that including chaff at an overall inclusion rate of $30 \%$ or more can lead to longer and slower eating periods, (can be more than double in duration), with a concomitant increase in chewing. This is likely to result in increased saliva production and improved buffering against acid in the stomach following consumption of carbohydrate-rich concentrates.

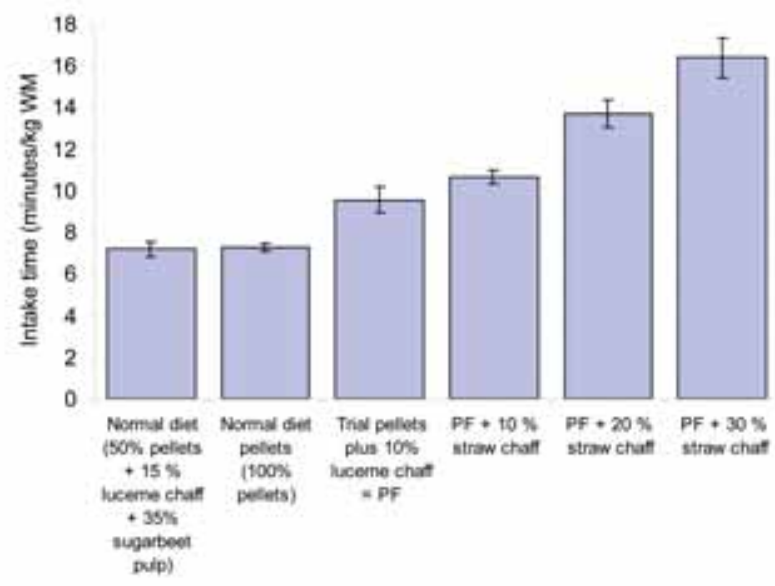

Fig 3 Time taken to eat a $\mathrm{Kg}$ of each of the diets (Ellis et al 2005). Fesszeiten für jeweils ein Kilo unterschiedlicher Futtermittel.

In a companion study, the effects of including chaff at the time of feeding, as opposed to being included in a manufactured ration, were investigated (Campbell et al 2005). Each morning, six geldings were fed a constant meal of oats (3 $\mathrm{g} / \mathrm{kg}$ bodyweight) in combination with either longer or shorter ground lucerne chaff $(4 \mathrm{~cm}$ and $<2 \mathrm{~cm}$, respectively) at five inclusion rates ranging from $7 \%$ to $37.5 \%$ of the total mixed ration. The rate of feed intake declined with increasing addition of chaff, and this effect was maximal when chaff made up $33 \%$ of the ration, which is in close agreement with the previous study. Also in common with the previous study, the rate of food intake was unaffected by chaff length. In the third and fourth studies in this series, the effects of including short $(<2 \mathrm{~cm})$ lucerne chaff with either a sweet concentrate mix (Harris et al 2005a) or an oat meal (Harris et al 2005b) at $6 \%$ and $26 \%$ of the total fed ration (6 and $35 \%$ addition on top of the core rations) were investigated. Prior to the study starting, the intake of $2-\mathrm{kg}$ hay over a 2 -hour period each morning was determined. This morning meal was then replaced by the concentrate mix or oats, which were both fed at a constant rate of $3 \mathrm{~g} /-\mathrm{kg}$ bodyweight. As well as monitoring feed intake, blood samples were collected over a 7 -hour period to assess the glycaemic response to the meal. The rate of feed intake was slowest during the period that hay was fed in both studies $(31 \mathrm{~g} / \mathrm{min})$. The sweet feed and oats were ingested at about twice the rate of hay $(77$ and $58 \mathrm{~g} / \mathrm{min}$ respectively). The addition of $6 \%$ chaff to the concentrate mix did not alter the rate of intake, but an apparent decrease in the rate of intake was seen with the $26 \%$ chaff $(49$ and $52 \mathrm{~g} / \mathrm{min}$ for the sweet feed and oats respectively) although this was not statistically significant (see Fig 4). This was due in part to an increased volume of intake per minute, particularly with the oat meal. This could potentially increase the risk of complications like oesophageal impaction associated with more rapid feed intake and reduced chewing. There was no correlation between rate of feed intake and the area under the curve (AUC) for blood glucose concentrations. The AUC and peak blood glucose level was significantly higher for the sweet feed compared with hay, and there was no significant effect of chaff inclusion on these parameters. Thus, the addition of chaff would seem unlikely to have an adverse effect on starch digestion in the small intestine, in that it does not appear to attenuate the glycaemic response to carbohydrate-rich feeds.

\section{Effect of adding chaff to a sweet feed}

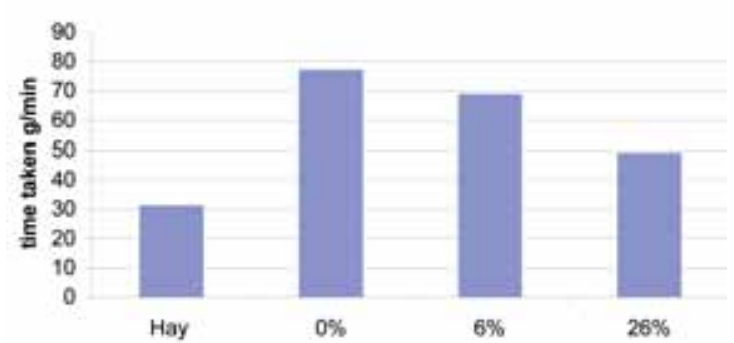

Fig 4 Effect of adding short $(<2 \mathrm{~cm})$ lucerne chaff to a sweet concentrate mix at 6 and $26 \%$ of the total ration (Harris et al. 2005a) Effekt der Zugabe von kurzem $(<2 \mathrm{~cm})$ Luzerne zu einer süßen Konzentratmischung in 6 und $26 \%$ der Gesamtration.

Differences between the studies in the UK and Australia may reflect differences in the basal meal type as well as the animals used as bodyweight and breed may have an influence (Campbell et al 2006). In addition, further investigations, (Campbell et al 2005, 2006); have suggested that this apparent difference is most likely due to the size of the meal fed and the length of the observation time in the different studies. 
This is because it appears that horses do not eat at a constant rate but have a more rapid rate of intake for the first 10 - 15 minutes of a meal and then slow their intake down by as much as a half. The UK study fed smaller meals $(1-1.2 \mathrm{~kg})$ which were eaten in under 20 mins whereas the Australian studies fed up to $2 \mathrm{~kg}$ and observed the horses eating for up to 45 mins. Thus it appears that chaff addition may be particularly effective with smaller meals or early in a larger meal at the time when horses are most at risk of eating too quickly. Clearly the addition of chaff can have real benefits for horses and further work is required to establish the type of chaff, its fibre length, means of feeding and inclusion rate to maximise these benefits.

\section{Other effects of feeding pre exercise that may affect performance}

A large full stomach may restrict the space available for lung expansion although there does not appear to be any published work on this. Gastrointestinal tract discomfort due to inappropriate rations or feeding practices may have an effect on performance (Harris et al 2006). In addition, following a meal blood flow is diverted to the gut to enable the products of digestion to be efficiently utilised - this may reduce the blood flow to working muscles and other organs where it may be better employed. Again there has been little work on this, although Duren et al 1992 looked at the influence of feeding and exercise on the distribution of intestinal and muscle blood flow in fed and fasted ponies. Blood flow to the locomotor and respiratory muscles was higher in fed than fasted animals - blood flow was shunted away from the GIT tract during exercise - but in the fed animals exercised at $\sim 75 \%$ of HR max they were able to increase heart rate and cardiac output and stroke volume to deliver an increased amount of blood to both the digestive tract and working muscle. Whether the same would apply to the faster exercising competition horse is currently not well understood.

\section{Current Recommendations}

Endurance Horse

Combining these tips we can provide suggestions as to the best practices that should be followed as illustrated below for the endurance horse pre race (Geor and Harris 2005). However, these need to be tailored for the individual animal and the circumstances.

- Training tends to be light in the 4-5 days before a race which combined with regular feeding will help to ensure that the glycogen stores are 'topped' up.

- Forage intake should be high before a ride and use good quality forage during the ride.

- Allow the horse to nibble on hay or other forage in the hours before the race starts but try not to start to exercise close to feeding a large concentrate/grain rich meal.

- It has been suggested that a high glycaemic meal the night before may be helpful to top up liver glycogen stores - but do not overload the small intestine $(<2 \mathrm{~kg}$ sweet feed/meal for $500 \mathrm{~kg}$ horse which has been adapted to having grain feeds).

- No information to support the use of electrolyte loading over the days pre a race as they are likely to be quickly excreted within a few hours
- Calcium and magnesium may compete for uptake etc so ensure that the calcium intake is not too high and that there is sufficient magnesium being provided.

- Electrolytes given a few hours before a prolonged exercise competition may be of value if adequate water is also provided and the horses are adequately hydrated - do not give excessive amounts of electrolytes.

Similar recommendations may apply to the Show jumper, as well as the Eventer.

\section{Race Horses}

Regardless of the discipline, adequate body carbohydrate stores are important for optimal exercise performance in the horse and this therefore includes the race- horse. It is very difficult to significantly increase the relatively slow rate of glycogen restoration in the horse following glycogen depleting exercise (see Jose-Cunilleras et al 2006), which means that it can be difficult to obtain optimal performance if individuals are raced within 48 (and potentially 72 ) hours of any significant glycogen depleting exercise. A slight reduction in training effort linked with maintenance of an appropriate diet should help to ensure that muscle and liver glycogen stores are as close to optimal as possible prior to undertaking the race. Restricting hay to $1 \%$ of $\mathrm{BW}$ in the few days before a race may have an advantage.

There is not sufficient published information however, to give precise advice re when or what to feed in the immediate period before a race but current suggested practices include keeping the pre exercise meals small in size $(<1 \mathrm{~kg})$ and ideally not within two to three hours of the race. In addition, perhaps $1 \mathrm{~kg}$ of forage should be provided in for example a double hay net/haylage net in the 2 -3hrs before a race to promote slow chewing and salivation without excessive gut fill etc. Given the recent work suggesting some advantage, with respect to gastric buffering, of feeding alfalfa hay (Nadeau et al 2000, Vervuert and Coenen 2004) it may be helpful if this forage was alfalfa or included alfalfa. However, more work is needed in this whole area before firm conclusions can be drawn.

\section{References}

Campbell T. E., Harris P. A., Doughty H. C. and Sillence M. N. (2005): Effect of chaff quantity and length on rate of intake in horses fed a concentrate diet. Asia Pacific Journal of Clinical Nutrition 14 (Suppl.), S80

Campbell T. E., Harris P. A., Doughty H. C. and Sillence M. N. (2006): Factors that affect the rate of intake when horses are fed a concentrate diet. In: Proceedings of the Australian Equine Science Symposium 1, 34

Clarke L. L., Roberts M. C. and Argenzio R. A. (1990): Feeding and digestive problems in horses: Physiologic responses to a concentrated meal. Vet. Clin. North Am. Equine Pract. 6, 433-450

Duren S. E., Manohar M., Sikkes B., Jackson S. and Baker J. (1992): Influence of feeding and exercise on the distribution of intestinal and muscle blood flow in horses. Pferedeheilkunde 9, 24-28

Ellis A. D., Thomas S., Arkell K. and Harris P. A. (2005): Adding chopped straw to concentrate feed: the effect of inclusion rate and particle length on intake behaviour of horses. Pferdeheilkunde 21, 35-36

Geor R. and Harris P .A. (2005): Feeding the endurance horse. In: Equine Nutrition for All, Harris P. A., Mair T. S., Slater J. D. and Green R. E. (eds) .Proceedings of the 1 st BEVA \& WALTHAM Nutrition symposia Harrogate. 139-140 
Harris P. A. and Graham-Thiers P. (1999): To evaluate the influence that "feeding" state may exert on metabolic and physiological responses to exercise. Equine Vet J. Suppl 30 Jeffcott L (ed), 633-636

Harris P. A. , Sillence M. Inglis R., Siever-Kelly C., Friend M., Munn K. and Davidson H. (2005a): Effect of short $(<2 \mathrm{~cm})$ lucerne chaff addition on the intake rate and glycaemic response to an oat meal. Proceedings of the 19th Equine Science Society symposium. Tuscon p151-152

Harris P. A., Sillence M. Inglis R., Siever Kelly C., Friend M., Munn K. and Davidson H. (2005b): Effect of short $(<2 \mathrm{~cm})$ lucerne chaff addition on the intake rate and glycaemic response of a sweet feed. Pferdeheilkunde 21, 88-89

Harris P., Coenen M., Frape D.L., Jeffcott L. B. and Meyer H. (2006): Equine nutrition and metabolic disease. In: Equine Manual Higgins, A. and Snyder J. (eds), Elsevier Saunders London p 151-222

Jose-Cunilleras E., Hinchcliff K. W., Sams R. A. and Devor S. T. (2002) Glycemic index of a meal fed before exercise alters substrate use and glucose flux in exercising horses. J. appl. Physiol. 92, 117-128

Jose-Cunilleras E., Hinchcliff K. W., Lacombe V. A., Sams R. A., Kohn C. W., Taylor L. E. and Devor S. T. (2006): Ingestion of starch-rich meals after exercise increases glucose kinetics but fails to enhance muscle glycogen replenishment in horses. Veterinary Journal 171, 468-477

Lawrence L. M., Soderholm L. V., Roberts A. M. and Hintz H. F. (1993): Feeding status affects glucose metabolism in exercising horses. J. Nutr. 123, 2151-2157

Lawrence L. M., Hintz H. F., Soderholm L. V. and Roberts A. M. (1995): Effect of time of feeding on metabolic response to exercise. Equine vet. J. Suppl. 18, 392-395

Nadeau J. A., Andrews F. M., Mathew A. G., Argenzio R. A., Blackford J. T., Sohtell M. and Saxton A. M. (2000): Evaluation of diet as a cause of gastric ulcers in horses. American Journal of Veterinary Research 61, pp. 784-790
Pagan J. D., Burger I. H. and Jackson S. G. (1995): The influence of time of feeding on exercise responses in thoroughbreds fed a fat supplemented or high carbohydrate diet. Equine Nutrition and Physiology 14th symposium proceedings p92-93

Pagan J. D. and Harris P. A. (1999): The effects of timing and amount of forage and grain on exercise response in Thoroughbred Horses. Equine Vet J. Suppl 30 Jeffcott L (ed) : 451-458

Palmgren Karlsson C., Jansson A., Essen-Gustavsson B. and Lindberg J. E. (2002): Effect of molassed sugarbeet pulp on nutrient utilisation and metabolic parameters during exercise. Equine Vet J suppl 34, 44-49

Rice O., Geor R., Harris P., Hoekstra K., Gardner S. and Pagan P. (2001): Effects of restricted hay intake on body weight and metabolic responses to high intensity exercise in thoroughbred horses. Proceedings of Equine Nutrition and Physiology society Lexington 273-279

Stull C. and Rodiek A. (1995): Effects of post prandial interval and feed type on substrate availability during exercise. Equine vet. J. Suppl. 18, 362-366

Vervuert I. and Coenen M. (2004): Nutritional risk factors of equine gastric ulcer syndrome. Pferdeheilkunde 20, 349-352

Patricia Harris MA PhD DipECVCN VetMB MRCVS

Equine Studies Group

WALTHAM Centre for Pet Nutrition

Waltham - on - the- wolds

Nr Melton Mowbray, Leics, LE 14 4RT

UK

pat.harris@eu.effem.com 